\title{
Healthcare Waste Composition and Generation Rate in Menellik II Referral Hospital, Addis Ababa, Ethiopia: A Cross Sectional Study
}

\author{
Desta Debalkie Atnafu", , Abera Kumie ${ }^{2}$ \\ ${ }^{1}$ Department of Health Service Management and Health Economics, School of Public Health, College of Medicine and Health Sciences, \\ Bahir Dar University, Bahir Dar, Ethiopia \\ ${ }^{2}$ Department of Environmental Health, School of Public Health, College of Health Sciences, Addis Ababa University, Addis Ababa, Ethiopia
}

Email address:

destad2a@gmail.com (D. D. Atnafu), aberakumie2@yahoo.com (A. Kumie)

${ }^{*}$ Corresponding author

\section{To cite this article:}

Desta Debalkie Atnafu, Abera Kumie. Healthcare Waste Composition and Generation Rate in Menellik II Referral Hospital, Addis Ababa, Ethiopia: A Cross Sectional Study. International Journal of Sustainability Management and Information Technologies.

Vol. 3, No. 2, 2017, pp. 10-19. doi: 10.11648/j.ijsmit.20170302.11

Received: February 20, 2017; Accepted: March 3, 2017; Published: April 14, 2017

\begin{abstract}
Healthcare facilities generate tremendous amount of infectious waste from healthcare activities. Despite the great potential for environmental hazards and public health risks of healthcare waste, its proper handling and management is significantly undermined in many developing countries where the actual amount of healthcare waste generated and its composition in Ethiopia is not well defined. Thus it is important to determine the existing generation rate in the hospital. Across-sectional study design was employed to assess the waste composition and determine generation rate in Menellik II hospital. A calibrated sensitive weight scale was used to quantify the generation rate of health care waste for seven days. Data was entered, arranged and analyzed using MS office excel sversion 2007 and SPS Sversion 20. Correlation and regression analysis were computed to know the relationships between magnitude of waste generated and other variables. The results showed that the mean waste generation rate was found to be $1.94 \mathrm{Kg} / \mathrm{bed} / \mathrm{day} \pm 0.335$, comprised of $40.9 \%$ $(130.20 \mathrm{Kg} /$ day \pm 38.22$)$ general and $59.1 \%(187.89 \mathrm{Kg} / \mathrm{day} \pm 38.85)$ hazardous wastes. The amount of waste generated was positively correlated with patients treated per day $(\mathrm{r}=0.835, \mathrm{p}<0.05)$. The waste generation rate and proportion was also significantly varies between inpatients and outpatients $(\mathrm{t}=4.353, \mathrm{P}<0.01)$ and there was a statistical significance difference among case teams $\left(X^{2}=56.558, p<0.0001\right)$. The mean generation rate in the hospital was comparable to other studies in Ethiopia but higher than Sub Saharan African countries. The proportion of hazardous waste (59.1\%) was above the threshold set by the WHO (10-25\%). This is because of malpractices of healthcare waste segregation. Therefore providing safe waste management technologies, adherence to national policy and awareness rising of all concerned needs to adopt in the hospital.
\end{abstract}

Keywords: Hospital, Case Team, Healthcare Waste, Generation Rate, Composition, Type of Waste, Addis Ababa

\section{Introduction}

Healthcare facilities were hub of cure, places to care the patient. From the commencement, the facilities are famous for the treatment of patients. However we are in the dark about the unfavorable impacts of the refuse generated by them on environment. The waste produced in the course of health care activities entails a higher risk of infection, injuries and detrimental effects on environment: poisonous missions from improper burning of medical waste, pollution of soil and water sources than any other type of waste [1,2]; and is the second dangerous after radiation wastes in the world [3-5].

Healthcare waste includes all wastes generated in the course of healthcare activities: diagnosis, treatment or immunization of both human beings and animals. Healthcare facilities such as hospitals, research laboratories, therapeutic and dental clinics, nursing centers, ambulance, mortuary and autopsy centers, etc. produce broad range of healthcare wastes [1].

The report at United Nation (UN) general assembly explained approximately 75 to $80 \%$ of the total waste 
generated by medical facilities is general waste and does not pose any risk to public health or the environment, the remaining waste is regarded as hazardous and may create a variety of health risks if not managed and disposed of in an appropriate manner $[1,5,6]$.

Unlike general wastes that do not require special handling, improper management of healthcare wastes from hospitals, clinics, and other health facilities poses occupational and public health risks to patients, health workers, waste handlers, haulers, and communities [1,5].

In developing countries, scavenger families who make a living of recycling materials from open unsanitary sites are at great risk especially from sharps waste. Hence, the management of healthcare wastes requires special attention and needs to be assigned high priority. This was supported research conducted by the World Health Organization (WHO) that estimates the unsterilized syringes cause between 8 to 16 million cases of hepatitis $\mathrm{B}, 2.3$ to 4.7 million cases of hepatitis $C$, and 80,000 to 160,000 cases of HIV every year $[1,7]$. Other estimate also shows that 5.2 million people in the world (including 4 million children) die each year from waste related diseases [5].

Majority of Healthcare facilities (HCFs) in developing counties suffer a variety of deprivations of healthcare waste management (HCWM) system starting from the point of waste generation up to the final disposal. An assessment done in 22 developing countries by WHO shows the proportion of Healthcare facilities (HCFs) that do not use proper waste disposal methods ranges from $18 \%-64 \%[1,8,9]$. A study conducted in Metro Manila revealed that although most of the hospitals perform waste segregation, less than $50 \%$ of the 144 hospitals studied did not have the proper mechanisms for proper waste handling and segregation. Only two out of five hospitals had an existing waste management committee and a separate budget allocation for waste management program [1]. Similarly, studies conducted earlier in Kenya by Japan International Cooperation Agency (JICA) and the Kenya Expanded Program on Immunization (KEPI) in conjunction with WHO showed that the HCWM practices encountered in most of the healthcare facilities do not comply with the international requirements to guarantee a safe and environmentally sound management of HCW (Healthcare waste) [10].

In most HCFs in Ethiopia, waste is not separated according to proper segregation methods and it is difficult to quantify the composition and amount of waste produced [11]. However with collection capacity of $65 \%$, the solid waste generation of Addis Ababa City was about $0.5 \mathrm{~kg}$ per capita per day and its density ranges from $205-370 \mathrm{Kg} / \mathrm{m}^{3}$ with a total $1,000,000 \mathrm{~m}^{3}$ volume of solid waste per annum. The remaining wastes were dumped along the streets, on vacant plots, along streams, in ditches and bridges in a manner of polluting the environment which makes the estimation more difficult [12].

The management of healthcare waste at hospitals in Addis Ababa city was poor resulting in increment of the proportion of generation of hazardous $\mathrm{HCW}$ which far from UN threshold report is deleterious to the public health and environment [13]). This was witnessed by the research made in the city that the total quantity of $\mathrm{HCW}$ generated at hospitals of Addis Ababa in 2011 was a median of 182.5 $\mathrm{kg}$ /day with an onrisk-HCW (median: $58.69 \%$, range: 46.89 $70.49 \%$ ) andriskHCW (median: $41.31 \%$, range: 29.5 $53.12 \%$ ) [13] And a similar study conducted in Amhara region by Tesfahune et al showed $56.4 \%$ as hazardous waste [14].

In developing countries, like Ethiopia, the quantity of healthcare waste has sharply risen in recent years as a result of rapid population growth and thus increasing demand for healthcare services. In spite of the large investment in expanding public and private healthcare facilities in Ethiopia, medical wastes are usually rampantly handled like any other municipal waste without any treatment in money urban setting of Ethiopia [12].

In many developing countries, there is a limited study about the quantity and composition of healthcare waste leads to in availability and inadequacy of data where the situation is much exacerbated in Ethiopia is one of the major reasons for inadequate and improper healthcare waste management. The waste disposed off indiscriminately mixing together with municipal wastes and even rarely dumped in to the rivers [11, $12]$.

Therefore this study was conducted with aim of evaluating waste composition and determining generation rate in Menellik II referral hospital in Addis Ababa city that could provide reliable information to policy makers and program designers for safe disposal of waste and to recommend appropriate healthcare waste management solutions.

\section{Methods and Materials}

\subsection{Study Design and Area}

An institution based cross-sectional study was conducted to quantify waste generation rate from February 17 to 24, 2015 in Menellik II referral hospital, Addis Ababa City. Addis Ababa is the capital city of Ethiopia, with the total population of $3,384,569$, within area of $527 \mathrm{~km}^{2}$ [15]. In the City there are 12 public and 36 private Hospitals, 84 health centers and 647 clinics. However, only the 6 public hospitals were under the city Administration Health Bureau and the rest were ruled by the Federal Ministry of Health. The hospital was opened in 1909 which has now 29 active specialized case teams and 199 numbers of beds. The daily visits of patients and their attendants to the hospital are found to be 646.

\subsection{Sampling Procedures}

Among the public hospitals providing healthcare service currently in the city administration, Menellik II referral hospital was selected purposively. The $7+1$ days of HCW measurements were conducted; following the protocol described by the WHO's for one hospital as followed a similar assumption used by debere et al [13], Tesfahun E. et al [14] and Tobin EA. et al in similar settings [16]. 


\subsection{Data Collection Tools and Procedures}

All healthcare case teams were observed and labeled prior to the actual HCW weighing: OPDs, pharmacy, imaging, laboratory, forensic pathology, inpatients (medical, surgical, ophthalmology, orthopedics), kitchen, lounges, operating rooms and administration offices. Waste collected from each case teams were measured and recorded on weighing scale recording data sheet using weight scale $\mathrm{N}$ electronic balance $\mathrm{XY} 1000 \mathrm{JB}$ number 1210223 readability, $0.1 \mathrm{~g}$ capacity ranges of $1.1 \mathrm{Kg}$ and UNICEF donated balance"EK5-fonds Des Nations Unies Pour L'Enfance" capacity of $120 \mathrm{Kg}$ at 8:00 am every morning for eight consecutive days to characterize waste generation. However, only the seven days HCW measurement data were used for estimation of generation rate and composition by dropping the first day generation for clearing cumulated wastes. The number of beds occupied and patients seen in outpatient recorded daily from liaison, triage and registration case teams were used for determination of relation of patient load to waste generation rate.

Plastic buckets of standard colors were arranged with biohazard plastic bags for each case teams. A yellow safety box was also used for sharps and syringes. All waste collection buckets, safety boxes and biohazard bags obtained for the study were labeled to indicate the different categories of healthcare waste, date of collection and name of case team. The waste classification and characterization was conducted in accordance with WHO guideline for developing countries.

\subsection{Data Quality Assurance}

Data quality was assured by relating the format logically to the variables measured. The tool was designed to measure all components of the variables and also adapt an existing instrument that was already used in other studies. Pre-test was conducted for one day prior to the actual data collection period to assure accuracy and validity of data collection tool. Weighing scale was calibrated using known $0.50 \mathrm{~kg}$, and $1 \mathrm{~kg}$ objects every morning before the actual measurement started for every data collection days. The quality of data was also maintained through training of data collectors and supervisor for a day and $\mathrm{HCW}$ data collection manual was provided for all data collectors and supervisor.

\subsection{Statistical Analysis}

The raw data collected from the field were entered and analyzed using MS excel window 2007 and SPSS version 20. The analysis was computed separately for each case teams grouped by inpatients and outpatients, and type of healthcare waste. The data distributions were explored normality test which were normally distributed. Descriptive statistics of frequency tabulation, count, mean, standard deviation and percentages were used to summarize generation of HCW into meaningful form. The result was also presented using tables, pie chart, graph and box plot. The healthcare waste generation rates were reported on the basis of $\mathrm{kg} / \mathrm{bed} / \mathrm{day}$, $\mathrm{kg} /$ patient/day and kg/outpatient/day, as described by Pruss and Tesfahune et al $[14,17]$.

The bivariate association between the quantities of total HCW generated and number of patients treated was tested using Pearson correlation coefficient. The number of patients visited the hospital, the total amount of waste generated and its type among various case teams was compared using Kruskal Wallis test as the data distribution was not homogeneous (with unequal variance) even when transformed. Linear regression was done to identify the variables that influence the quantity of wastes generated and select the best fit predictable models that can be used in estimating the waste generation rate of the hospital. The Ftest was used for the model fitness adequacy.

The waste characterization was conducted in accordance with (WHO) guidelines [17]. Based on the characterization the waste composition was reported using different descriptive statistics such as percentages to evidence the effect of segregation practice on the proportion of hazardous waste. Statistical test for significance was based on 5\% level of significance (95\% confidence level) and $r$ also reported for strength and direction of linear relationship of patient flow and $\mathrm{HCW}$ generation rate.

\subsection{Ethical Consideration}

Ethical clearance and official letter was obtained from School of Public Health, Addis Ababa University. Written permission for data collection was taken from Addis Ababa City Administration Health Bureau. Verbal and written consent was obtained from the manager of the hospital. Data collectors were provided data collection manual and trained to use personal protective devises while measuring healthcare wastes. On job health education related to hazardous waste management was given to workers immediately after data collection. Recommendation was given to hospital managers for improper HCW management practice based on what was observed during the assessment.

\section{Results}

\subsection{Background of Healthcare Waste by Source of Generation}

A total of 4524 patients visited the hospital within a week, of which $1151(25.44 \%)$ patients admitted to IPDs and the remaining was seen at OPDs. The average daily patient attendance over all in the hospital, inpatients and outpatients case teams were $646.29( \pm 284.85), 164.43( \pm 7.74), 481.86$ $( \pm 279.67)$ respectively (Table 1$)$. The variation of distribution of patient attendance in seven consecutive days was higher in outpatients and less in inpatients (Table 1). This was directly related to the variation of the service provision in the weekend. 
Table1. Daily attendance of patients and HCW generation in IPDs, OPDs and all case teams respectively (\%) in Menellik II referral hospital, Addis Ababa, February 2015.

\begin{tabular}{llll}
\hline Days of HCW measurement & No of Inpatients/ day & Outpatient attendance / day & Patient flow/day in all case teams (IPD+OPD) \\
\hline Wednesday* & $168(21.27)$ & $622(78.73)$ & $790(17.46)$ \\
Thursday & $165(22.60)$ & $565(77.40)$ & $730(16.14)$ \\
Friday & $159(19.56)$ & $654(80.44)$ & $813(17.97)$ \\
Saturday & $151(56.13)$ & $118(43.87)$ & $269(5.95)$ \\
Sunday & $163(77.25)$ & $48(22.75)$ & $211(4.66)$ \\
Monday & $171(21.98)$ & $607(78.02)$ & $778(17.20)$ \\
Tuesday & $174(18.65)$ & $759(81.35)$ & $933(20.62)$ \\
Total & 1151 & 3373 & 6424 \\
Mean & 164.43 & 481.86 & 646.29 \\
Standard Deviation & $( \pm 7.74)$ & $( \pm 279.67)$ & $( \pm 284.85)$ \\
HCWKg/day & $200.71 \pm 26.56$ & $117.57 \pm 42.99$ & \\
\hline
\end{tabular}

*Starting day of data collection

\subsection{Generation rate of $\mathrm{HCW}$ and Characteristics}

The average total HCW generation rate of the hospital was estimated to be $0.493 \mathrm{~kg} / \mathrm{staff} /$ day, $1.94 \mathrm{Kg} / \mathrm{bed} /$ day and 0.49 $\mathrm{Kg} /$ total patient/day by weight, and $0.012 \mathrm{~m}^{3} / \mathrm{bed} /$ day by volume yielding a density of $160.95 \mathrm{~kg} / \mathrm{m}^{3}$ (Table 2). Of Which $0.79 \mathrm{Kg} / \mathrm{bed} /$ day $(40.91 \%)$ was general waste and $1.15 \mathrm{Kg} / \mathrm{bed} /$ day $(59.09 \%)$ was accounted to hazardous. The average generation rate estimation of hazardous and general waste has a statistical significance difference $(\mathrm{t}=2.796$, $\mathrm{p}<0.05$ ), generation of hazardous waste was nearly 1.5 times that of general waste. Whereas, of the volume of $\mathrm{HCW}$ generated, infectious waste was the largest volume $55.65 \%$ $\left(0.0067 \mathrm{~m}^{3} / \mathrm{bed} /\right.$ day $)$ and pressurized containers $0.02168 \%$ $(0.000002 \mathrm{Kg} / \mathrm{bed} /$ day) was the smallest one (Table 2$)$.

Table 2. Dailygeneration rates by types of HCW (Mean, SD) in Menellik II referral hospital, Addis Ababa, February, 2015.

\begin{tabular}{|c|c|c|c|c|c|c|}
\hline Type of HCW & Mean & SD & $\mathrm{Kg} / \mathrm{bed} / \mathrm{day}$ & $\mathrm{Kg} / \mathrm{OP} * * /$ day & Kg/TP*/day & $\mathrm{m}^{3} / \mathrm{bed} / \mathrm{day}$ \\
\hline General & 130.20 & 38.22 & 0.79 & 0.27 & 0.201 & 0.0049 \\
\hline Infectious & 170.93 & 35.48 & 1.042 & 0.355 & 0.265 & 0.0067 \\
\hline Pathological & 1.643 & 2.688 & 0.01 & 0.0034 & 0.00254 & 0.000097 \\
\hline Pharmaceuticals & 4.37 & 2.86 & 0.027 & 0.0091 & 0.00677 & 0.000197 \\
\hline Radiological & 5.36 & 0 & 0.033 & 0.0111 & 0.0083 & 0.000061 \\
\hline Pressurized & 0.254 & - & 0.00022 & 0.000075 & 0.000056 & 0.000002 \\
\hline
\end{tabular}

$* \mathrm{TP}=$ Total patient $(\mathrm{IPD}+\mathrm{OPD}) * * \mathrm{OP}=$ Outpatient only

\subsection{Health Care Waste Composition}

The composition of generation of infectious, general, sharp, radiological, pharmaceutical, pathological and pressurized containers compared from total HCW stream was $53.73 \%, 40.91 \%, 1.77 \%, 1.68 \% 1.38 \%, 0.52 \%$ and $0.01 \%$ respectively (Figure 1: A).
Regarding the composition of healthcare waste, almost similar in inpatients and outpatients except general healthcare waste $28 \%$ in inpatients and $43 \%$ in outpatients. The infectious waste was $86 \%$ in inpatients whereas $46 \%$ in outpatients (Figure 1: B\& C). These proportional variations have a statistical significance with P-value less than 0.05 .

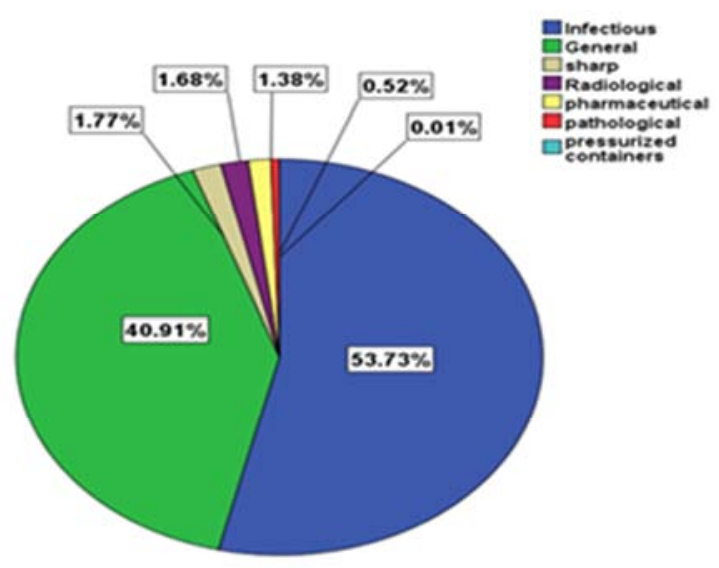

A. Total waste stream 


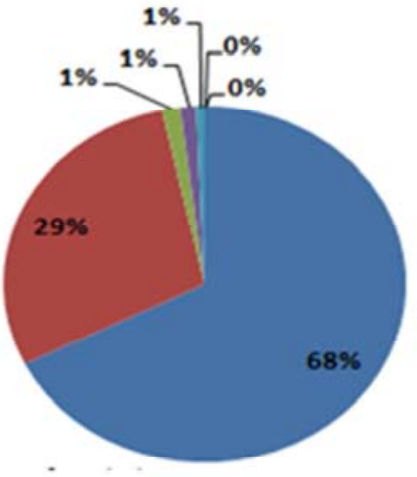

B. Inpatients

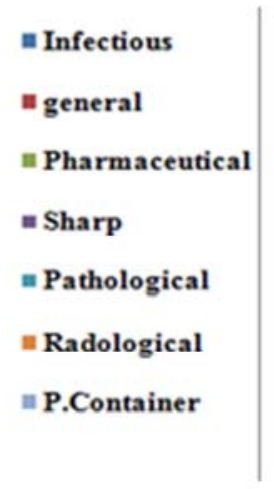

C. Outpatients

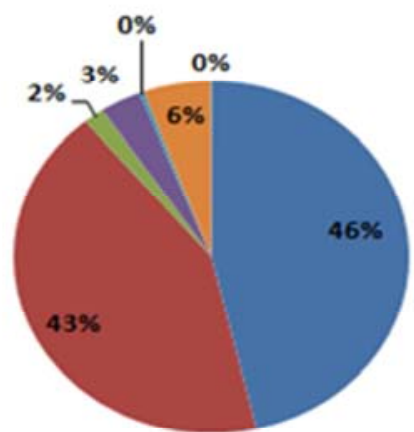

Figure 1. The composition contribution and generation of HCWs in inpatients, outpatients\& total HCW stream in Menellik II hospital, Addis Ababa, February 2015 .

In most of the case teams, general waste was the second leading generated waste next to infectious waste than the rest category of wastes (Table 3). Pathological waste was generated only in operating room $(4.47 \%)$ and laboratory $(4.87 \%)$ where as sharp waste was larger in laboratory
(12.31\%), outpatients $(5.13 \%)$ and surgical IPD (2.21\%). The largest generation of $\mathrm{HCW}$ by Volume was occurred in medical IPD $0.39 \mathrm{~m}^{3} /$ day $(19.94 \%)$ and out patients $0.308 \mathrm{~m} 3 /$ day $(15.59 \%)$.

Table 3. Amount of HCW generated and their composition by type of $\mathrm{HCW}$ (Kg/7 days) and (\%) in each case team in Menellik II hospital, Addis Ababa, February 2015.

\begin{tabular}{|c|c|c|c|c|c|c|c|c|}
\hline \multirow[t]{2}{*}{ Names of Case teams } & \multicolumn{7}{|c|}{ Composition of $\mathrm{HCW}(\mathrm{Kg} / 7$ days) (\%) } & \multirow[b]{2}{*}{$\begin{array}{l}\text { Volume } \\
\left(\mathrm{m}^{3} / \text { day }\right)\end{array}$} \\
\hline & General & Infectious & Pathological & Sharps & $\begin{array}{l}\text { Pharma } \\
\text { ceutical }\end{array}$ & $\begin{array}{l}\text { Radiolo } \\
\text { gical }\end{array}$ & $\begin{array}{l}\text { Pressurized } \\
\text { container }\end{array}$ & \\
\hline Orthopaedic IPD & $64.5(26.94)$ & $174(72.68)$ & - & $0.901(0.38)$ & - & - & - & $0.186(9.42)$ \\
\hline Medical IPD & $151.19(31.81)$ & $310(65.27)$ & - & $7.838(1.65)$ & $6(1.26)$ & - & - & $0.3939(19.94)$ \\
\hline Surgical IPD & $67.56(25.63)$ & $184.29(69.63$ & - & $5.83(2.21)$ & $6(2.28)$ & - & - & $0.2873(14.54)$ \\
\hline Ophthalmology IPD & $66.3(61.75)$ & $40.5(37.72)$ & - & $0.58(0.54)$ & - & - & - & $0.053(2.68)$ \\
\hline OPD & $112.9(35.30)$ & $190.3(59.49)$ & - & $16.42(5.13)$ & - & - & $0.254(0.08)$ & $0.308(15.59)$ \\
\hline Laboratory & $8.5(16.56)$ & $28(54.56)$ & $2.5(4.87)$ & $6.38(12.31)$ & $6(11.69)$ & - & - & $0.054(2.73)$ \\
\hline Forensic pathology & $12(12.12)$ & $87(87.88)$ & - & - & - & - & - & $0.086(4.35)$ \\
\hline OR & $28.14(13.99)$ & $155.5(77.31)$ & $9(4.47)$ & $1.5(0.75)$ & $7(0.48)$ & - & - & $0.264(13.37)$ \\
\hline Imaging & $10(18.01)$ & $8(14.41)$ & - & - & - & $37.52(67.58)$ & - & $0.027(1.37)$ \\
\hline Laundry & - & $19(100)$ & - & - & - & - & - & $0.02(1.1)$ \\
\hline FoodCatering & $99(100)$ & - & - & - & - & - & - & $0.04(2.03)$ \\
\hline Lounges & $228(100)$ & - & - & - & - & - & - & $0.15(7.6)$ \\
\hline Administration & $17(100)$ & - & - & - & - & - & - & $0.03(1.3)$ \\
\hline
\end{tabular}

\subsection{Comparison of Healthcare Waste Generation Rate Among Case Teams}

Patient flow, total healthcare waste and its types (general and hazardous waste) were compared among different case teams Kruskal Wallis test to check for the presence of statistically significant difference of generation of $\mathrm{HCW}$. There was statistically significant difference of mean of patient flow $\left(X^{2}=37.859, p<0.0001\right)$, total healthcare waste $\left(X^{2}=56.558, p\right.$ $<0.0001)$, general HCW $(\mathrm{X} 2=32.474, \quad \mathrm{p}<0.0001)$ and hazardous waste $\left(X^{2}=49.987, p<0.0001\right)$ among different case teams (Table 4). This showed that a type or specialty of case teams was a factor for generation of $\mathrm{HCW}$.

Table4. Comparison of patient flow, total HCW generation and its type using Kruskal Wallis test in each case teams in Menellik II Hospital, Addis Ababa, February 2015.

\begin{tabular}{lllll}
\hline \multirow{2}{*}{ Types of Case teams } & \multicolumn{3}{c}{ Mean Rank } & Hazardous HCW \\
\cline { 2 - 5 } & Patient flow & Total HCW & 41.64 & 61.93 \\
Medical IPD & 32.79 & 71.71 & 27.00 & 44.79 \\
Surgical IPD & 25.21 & 52.29 & 21.79 & 40.64 \\
Orthopaedic IPD & 18.86 & 50.21 & 21.71 & 22.00 \\
Ophthalmology IPD & 11.00 & 28.71 & 33.58 & 47.57 \\
OPD & 37.14 & 57.50 & 15.63 & 41.07 \\
OR & - & 42.43 & 10.50 & 18.57 \\
Imaging & - & 13.79 & 29.00 & 30.25 \\
Forensic pathology & 4.00 & 29.67 & & \\
\hline
\end{tabular}




\begin{tabular}{lllll}
\hline \multirow{2}{*}{ Types of Case teams } & \multicolumn{4}{c}{ Mean Rank } \\
\cline { 2 - 5 } & Patient flow & Total HCW & General HCW & Hazardous HCW \\
\hline Laboratory & - & 13.50 & 3.75 & 18.29 \\
Pharmacy & - & 13.57 & 25.00 & 4.50 \\
Lounges & - & 48.86 & 46.43 & - \\
$\mathrm{X}^{2}$ & 37.859 & 56.558 & 32.474 & 99.987 \\
$\mathrm{df}$ & 5 & 10 & 10 & 9 \\
P-value & 0.000 & 0.000 & 0.000 & 0.000 \\
\hline
\end{tabular}

As the box plot shows below, there was statistically significant higher mean generation of total $\mathrm{HCW}(\mathrm{p}<0.01)$ and hazardous HCW $(\mathrm{p}<0.0001)(\mathrm{kg} /$ day $)$ in IPDs than OPDs case teams as shown below. The generation rate of general HCW in OPDs was almost similar to IPDS.
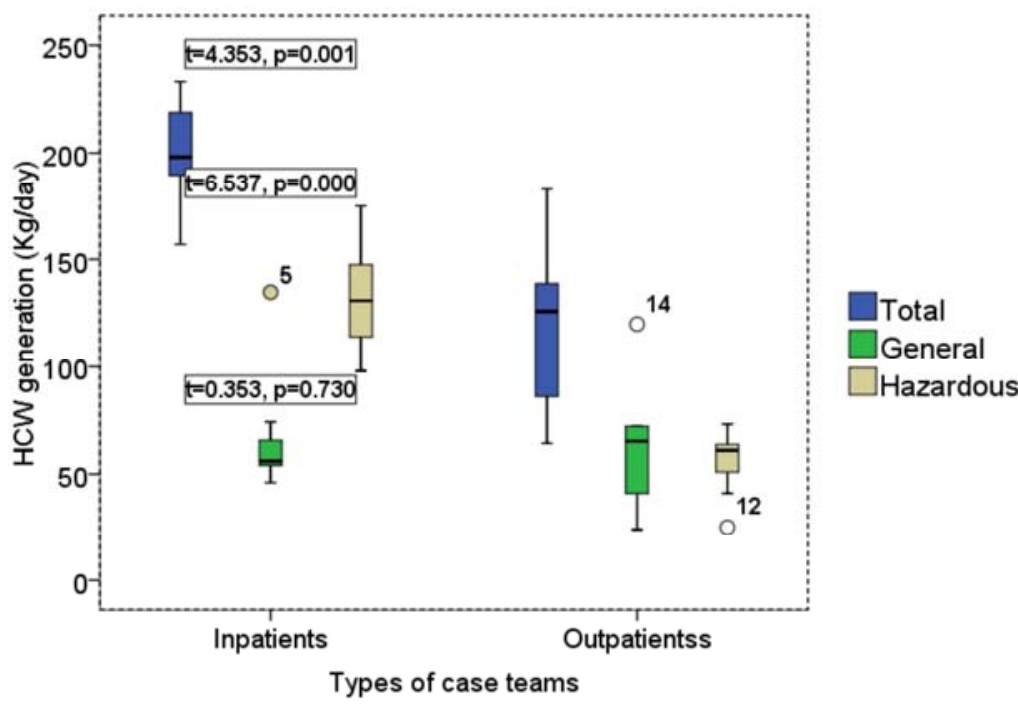

$\mathrm{O}=$ outliers

Figure 2. Box plot of healthcare waste generation rate ( $\mathrm{kg} /$ day) in the IPD and OPD case teams, median with interquartile ranges, Menellik II hospital Addis Ababa, Ethiopia, February 2015.

\subsection{Correlation of Patient Flow with HCW Generation Rate}

The number of patients treated (bed occupancy) with amount of generation of total healthcare waste and its type (general and Hazardous) was evaluated for their linear relationship Pearson correlation coefficient (r) (table 5). The correlation coefficient showed that there was a positive linear relationship as number of patients visited (beds occupied) increased, total healthcare wastes and general also increased in most case teams even though not statistically significant. A strong positive statistically significant linear relationship was observed between number of outpatients and total $\mathrm{HCW}$ generated at OPDs $(r=0.901$, $p$-value $<0.01)$ which was a bit far from a perfect linear relationship $(\mathrm{r}=1)$ where as a negative linear relationship was observed at Orthopedic IPD $(r=-0.248)$. There was also a statistically significant strong positive linear relationship between number of patients and generation of general HCW in surgical IPD $(r=0.988$, pvalve $<0.01$ ). A negative linear relationship was seen in most case teams except OPDs in the case of hazardous HCW. There was no relationship between patient flow and HCW generated in Ophthalmology IPD.

Table 5. Correlation of visitors and quantity of waste (total HCW, general HCW, and Hazardous HCW) generated in a day in each case teams in Menellik II hospital Addis Ababa, February, 2015.

\begin{tabular}{lllllll}
\hline $\begin{array}{l}\text { Name of Case } \\
\text { teams }\end{array}$ & Total HCW & & General HCW & & Hazardous HCW \\
\cline { 2 - 7 } & $\begin{array}{l}\text { Pearson correlation } \\
\text { Coefficient (r) }\end{array}$ & P-value & $\begin{array}{l}\text { Pearson correlation } \\
\text { Coefficient (r) }\end{array}$ & p-value & $\begin{array}{l}\text { Pearson correlation } \\
\text { Coefficient (r) }\end{array}$ & p-value \\
\hline Medical IPD & 0.112 & 0.81 & 0.221 & 0.634 & -0.041 & 0.93 \\
Surgical IPD & 0.545 & 0.206 & $0.988^{*}$ & $0.002^{*}$ & -0.062 & 0.894 \\
Orthopaedic IPD & -0.248 & 0.592 & 0.393 & 0.383 & -0.374 & - \\
Ophthalmology IPD & 0 & - & 0 & - & 0 & 0.408 \\
OPDs** & $0.901^{*}$ & $0.006^{*}$ & 0.654 & 0.159 & 0.748 & 0.0 .53 \\
Forensic pathology & 0.327 & 0.527 & 0 & - & -0.381 & 0.456 \\
\hline
\end{tabular}

*P-value $<0.01$-statistically significant; ** OPDs excludes generation of laboratory and imaging case teams. 
Figure 3 was a scatter plot between the daily amounts of HCW generated and the number of patients visited the hospital for healthcare services. A linear trend was evident between amount of total $\mathrm{HCW}$ generation and total number of patients (statistically significant, $\mathrm{P}<0.05 ; \mathrm{R}^{2}=0.698$ ). The fitted model was also adequate $(\mathrm{F}=11.72, \mathrm{P}<0.05)$. Therefore, the number of patients visited the hospital daily can be used as a predictor of HCW generation rates in the hospital. This $\mathrm{R}^{2}$ also showed a moderately strong linear relationship between numbers of patients visited the hospital and amount of HCW generated in particular, $69.8 \%$ of the variability among the observed values of HCW generation in seven days of HCW measurement was explained by the linear relationship between numbers of total patients visited the hospital and generation of $\mathrm{HCW}(\mathrm{P}<0.05)$. The remaining $30.2 \%$ of the variation was not explained by this relationship or due to unknown factors.

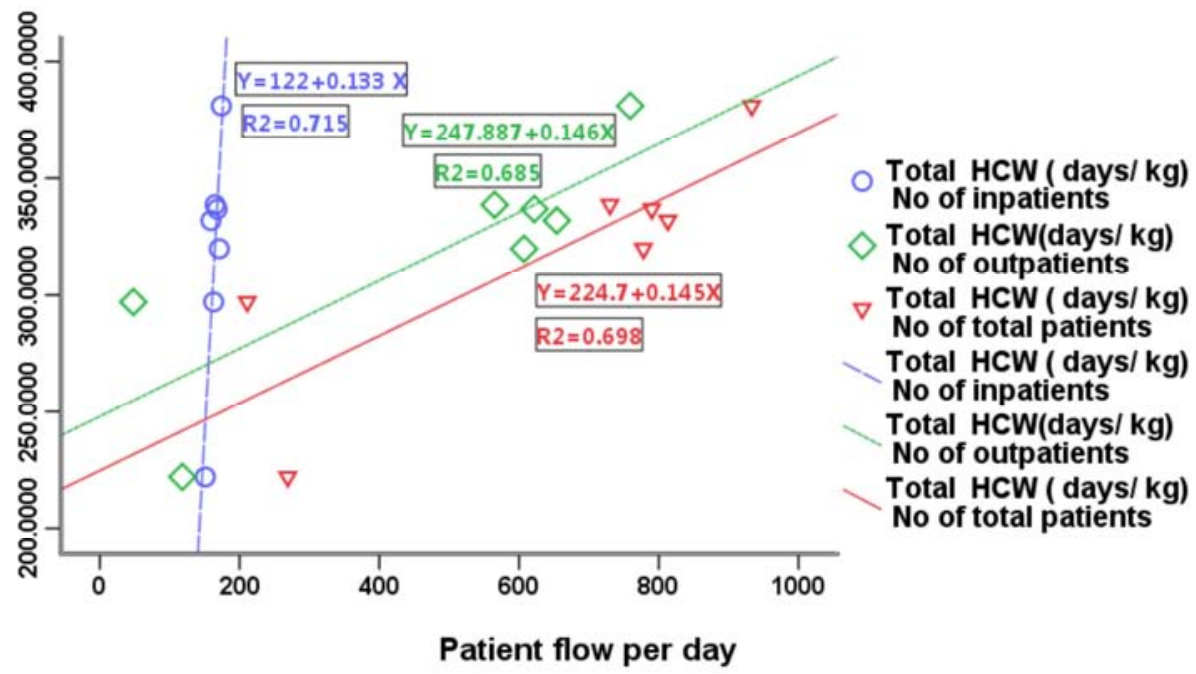

Figure 3. Scatter plot of total HCW generation (Kg/day) versus number of inpatients, outpatients and total patients visited Menellik II hospital, February 2015 .

\subsubsection{Models for the Estimation of Hospital HCW Generation Rate}

The variables that affect the quantity of HCW generated were identified important to develop best fit predictive models for the estimation of hospital waste generation rate: patient flow, type of case team (inpatient vs. outpatient) and type of HCW (general vs. hazardous) and linear regression was done to select the best fit predictive models as shown below (Table 6).

Table 6. Statistical characteristics of the model for the variables that predicts the generation rate in Menellik II hospital, February 2015.

\begin{tabular}{|c|c|c|c|c|c|c|c|c|c|c|c|c|}
\hline \multirow{2}{*}{$\begin{array}{l}\text { No of } \\
\text { models }\end{array}$} & \multirow{2}{*}{$\begin{array}{l}\text { Model } \\
\text { Variables }\end{array}$} & \multirow{2}{*}{$\begin{array}{l}\text { Parameter } \\
\text { estimate }\end{array}$} & \multirow{2}{*}{$\begin{array}{l}\text { Std. } \\
\text { Error }\end{array}$} & \multirow[b]{2}{*}{$\mathbf{R 2}$} & \multirow[b]{2}{*}{ t-Value } & \multirow{2}{*}{$\begin{array}{l}\alpha- \\
\text { level. }\end{array}$} & \multicolumn{2}{|l|}{$95.0 \%$ CI } & \multirow[b]{2}{*}{$\mathbf{F}$} & \multirow{2}{*}{$\begin{array}{l}\alpha \text {-level } \\
\text { for } F\end{array}$} & \multirow{2}{*}{ df } & \multirow[b]{2}{*}{ Predictive models } \\
\hline & & & & & & & $\begin{array}{l}\text { Lower } \\
\text { Bound } \\
\end{array}$ & $\begin{array}{l}\text { Upper } \\
\text { Bound }\end{array}$ & & & & \\
\hline \multirow[t]{3}{*}{1} & $\begin{array}{l}\text { Total } \\
\text { patients }\end{array}$ & 0.145 & 0.042 & $\begin{array}{l}0.70 \\
1\end{array}$ & 3.424 & 0.019 & 0.036 & 0.255 & 11.72 & 0.019 & 6 & \multirow{2}{*}{$\begin{array}{l}\mathrm{Y} \\
(\mathrm{Kg} / \text { day })=224.555+0.145^{*} \sharp \mathrm{T} \\
\text { otal patients }\end{array}$} \\
\hline & Intercept & -279.51 & 260.72 & & -1.072 & 0.344 & -1003.39 & 444.37 & & & & \\
\hline & Inpatient & 3.389 & 1.671 & & 2.028 & 0.112 & -1.251 & 8.029 & 10.99 & 0.024 & 6 & No adequacy \\
\hline \multirow[t]{3}{*}{2} & Outpatient & 0.085 & 0.046 & $\begin{array}{l}0.84 \\
6\end{array}$ & 1.829 & 0.141 & -0.044 & 0.213 & & & & \\
\hline & Intercept & -1.692 & 1.715 & & -0.987 & 0.380 & -6.453 & 3.069 & & & & \multirow{3}{*}{$\begin{array}{l}\mathrm{Y}(\mathrm{kg} / \text { day })=1.005 * \text { Hazardous } \\
(\mathrm{Kg} / \text { day })+1.01 * \text { General } \\
(\mathrm{Kg} / \text { day })\end{array}$} \\
\hline & Hazardous & 1.005 & 0.007 & & 147.731 & 0.000 & 0.986 & 1.024 & & & & \\
\hline \multirow[t]{3}{*}{3} & General & 1.010 & 0.007 & 1 & 145.773 & 0.000 & 0.991 & 1.030 & 18109 & 0.000 & 6 & \\
\hline & Hazardous & 0.974 & 0.010 & & 102.395 & 0.000 & 0.933 & 1.015 & & & & \multirow{3}{*}{$\begin{array}{l}\mathrm{Y}(\mathrm{kg} / \text { day })=0.974 * \text { Hazardous } \\
(\mathrm{Kg} / \text { day })+0.996 * \text { General } \\
(\mathrm{Kg} / \text { day })\end{array}$} \\
\hline & General & 0.996 & 0.007 & & 136.599 & 0.000 & 0.965 & 1.028 & & & & \\
\hline 4 & Inpatients & 0.014 & 0.039 & 1 & 0.374 & 0.745 & -0.152 & 0.181 & 31669.8 & 0.000 & 6 & \\
\hline
\end{tabular}

Acceptable $\alpha$-level (level of significance) $=0.100$; F represents general linearity test; $\mathrm{R}^{2}$ represents coefficient of multiple determination; df represents degree of freedom; and t represents - importance of model variables. 


\section{Discussion}

Healthcare waste handling alternatives are different in Ethiopia. One of the important matters in the process of establishing a reliable waste management plan involves a periodic quantification of the generation rate.

The median quantity of $\mathrm{HCW}$ generation $(0.43$ $\mathrm{Kg} /$ patient/day or $2.01 \mathrm{Kg} / \mathrm{bed} /$ day) was in the range of median generation of the study conducted in public and private hospitals of Addis Ababa (0.361-0.669 kg/patient/ day) [13] and a study in Hawassa city HCFs by Haile Michael et al (1.48-8.19 kg/bed/day) [18]. This result was also almost similar to the report by Tesfahune et al $(0.31 \mathrm{Kg} / \mathrm{patient} / \mathrm{day})[14]$. This fitness in generation rate was due to similar in $\mathrm{HCW}$ management systems, waste characterization and classification as well as enforcement of laws and regulation of the country which enables them to follow the same procurement policies for the purchase and consumption of commodities in the same socioeconomic conditions. The more the clients vary in level of income, the more difference in health seeking behavior and expenditure for treatment.

The mean of HCW $(0.49 \mathrm{~kg} /$ patient $/$ day or 1.94 $\mathrm{Kg} / \mathrm{bed} /$ day) in this study was greater than what was studies done in Khartoum state hospitals $(0.38 \mathrm{~kg} /$ beds/day) [2], SubSaharan countries (0.3-1.5 kg/bed/day) [17], Pakistani hospitals $(1.35 \mathrm{~kg} / \mathrm{bed} / \mathrm{day})$ [4], and Nigeria between 0.562 $0.670 \mathrm{~kg} / \mathrm{bed} /$ day [19]. This variation could be attributed to the differences in season of the year the studies were conducted. This study was undertaken in non-harvesting season could increase the health seeking behavior of patients and highly increases the patient load in the hospital which intern increases generation $\left(\mathrm{P}<0.05 ; \mathrm{R}^{2}=0.698\right)$. Improper waste characterization and poor HCWM system in the country has limited chance of reduction and recycling wastes which increases generation in the hospital is also the possible explanation [20].

The amount of healthcare waste generation rate in different case teams was significantly different $\left(\mathrm{X}^{2}=56.558\right.$, $\mathrm{p}<0.0001)$. Large amount of HCW was generated in Medical IPD $0.164 \mathrm{Kg} /$ patient/day $(21.33 \%)$. This was greater than the generation in Nigeria primary HCFs labor ward $(0.003 \pm 0.002$ $\mathrm{kg} /$ person/day) [16] and smaller than the result found by Komilis et al, 2012 in pathology clinic $(0.66 \mathrm{~kg} / \mathrm{bed} / \mathrm{day})$ [21]. The variation of generation among hospitals' case team may be attributed to variation of seasons, the specialty and rank of healthcare hospital and department, the numbers and health condition of patients treated in, kind of healthcare delivery, type and nature of waste generated, segregation practice. Komilis et al., mentioned in their report that it is risky to make comparisons with $\mathrm{HCW}$ records from other countries, due to the variability in the definitions and methods of classifications of $\mathrm{HCW}$ throughout the world [21].

Similarly, there was also a difference in generation rates of $\mathrm{HCW}$ between OPDs and IPDs. The total quantity of HCW generated from IPDs $(1.22 \mathrm{~kg} / \mathrm{bed} /$ day $)$ was significantly more than OPDs $(0.244 \mathrm{~kg} /$ outpatient/day $)$. The mean generation rate in $\mathrm{kg} / \mathrm{bed} / \mathrm{day}$ (IPD) was therefore nearly five times greater than the generation rate estimated in $\mathrm{kg} /$ outpatient/day $(\mathrm{OPD}) \quad(\mathrm{t}=4.353, \mathrm{p}<0.01)$. This relationship showed that point of $\mathrm{HCW}$ generation was a significant predictor of generation rate. This was support by the study conducted in hospitals of Amhara regional state that revealed the total generation rate of $\mathrm{HCW}$ from inpatients ranged from 0.25 to $2.77 \mathrm{~kg} / \mathrm{bed} /$ day (median: 1.67 $\mathrm{kg} / \mathrm{bed} /$ day) was higher than $0.21-0.65 \mathrm{in} \mathrm{kg} /$ patient/day (median: $0.34 \mathrm{~kg} /$ patient/day) from outpatients [14]. This generation in the outpatient was also higher than in primary HCFs of Nigeria outpatient unit $(0.02 / \mathrm{kg} /$ outpatient/day $)$ [16]. The reason for such difference is the higher the rank of the facility, the probability of the patient treated in it is greater as result of referral linkage and hence the higher quantity of hospital healthcare waste generation which is related to the high supply and provision of healthcare services. Average length of stay of patients is also greater in the secondary HCFs which need much number of staff which indirectly increases the generation rate [1].

The proportional value of the hazardous component in the total healthcare waste stream is above $50 \%$ in both outpatient and inpatients in the hospital. The total HCW consists of $59.09 \%$ hazardous HCW, $53.73 \%$ infectious waste and $1.77 \%$ sharps which was substantially above the WHO recommendation for developing countries and threshold set by WHO: $10-25 \%$ hazardous waste, $15 \%$ infectious and $1 \%$ sharps waste $[6,17,20,22]$. The major reason for the high percentage of hazardous waste in hospitals of developing countries appears to be the improper segregation of different types of waste materials by health professionals as shown by Debere et al [13], Hayla Michael et al [18] and inadequate orientation of auxiliary staff and health workers. For example, research carried out on risk perception of healthcare workers towards healthcare waste management in Ethiopia showed that only a small proportion of healthcare workers adequately perceived the health risk of handling condition of waste materials [23]. This deficiency is linked with inadequate training and supervision of health workers and, lack of enforceable health regulations aimed at providing a safe working environment at healthcare facilities through managing waste disposal.

The proportion of hazardous waste generated in the Menellik II hospital (Figure 1) was at the high end of the spectrum (nearly 1.5 times its non-risk waste $(\mathrm{t}=2.796$, $\mathrm{P}<0.05)$ ) when compared with that found in hospitals of other developing countries: 20\% in Pakistan [24], 20-25\% in Turkey [5], 20\% in Bangladesh [5], 26.5\% in Nigeria [19], $50 \%$ in Tanzania and $2-10 \%$ in SSA $[17,25,26]$. This showed that the type of HCW category was a factor used to predict the total HCW generation rate [14]. The difference may be regulations, policies and methods on waste classification and characterization, monitoring and enforcement of HCWM system by respective bodies, 
inventory control, and extent of recycling. The higher hazardous $\mathrm{HCW}$ generation rate at Menellik II was also probably due to the fact that it was the only forensic pathology service in it and thus serving a larger number of morgues in comparison with other hospitals. The use of disposable materials and increase of emergence of new body fluid associated disease also likely increase the amount of hazardous waste generated.

The mean HCW generation at the hospital estimated 0.49 $\mathrm{kg} /$ patient/ day, with the density of $160.95 \mathrm{~kg} \mathrm{~m}^{-3}$ and the volume of HCW was recorded $0.0031 \mathrm{~m}^{3} /$ patient/day. This generation interims of volume and density was different from the study conducted about solid waste generation rate in Addis Ababa city in 2014: $0.5 \mathrm{~kg} /$ capita/day, the density between 205 to $370 \mathrm{~kg} \mathrm{~m}^{-3}$ and the volume 0.00079 $\mathrm{m}^{3} /$ patient/day [12]. This discrepancy might be due to the study area, type and nature of waste generated in the hospital which completely deferent from the city households. The waste collection efficiency and compaction rate also the likely reason.

The total healthcare waste generation rate in the hospital $\mathrm{kg}$ /day was $318.11 \pm 49.34 .91$ (Table 2), in OPDs $117.57 \pm 42.99$ and in IPDs 200.71 \pm 26.56 (Table 1), the reasons for this higher standard deviation and high estimation of generation in the hospital and out patients is due to the weekend days. The numbers of outpatients were less compared to all the regular days and the numbers of inpatients were followed in all days of the week. However, the healthcare waste generation rate is highly influenced by the number of inpatients due to the fact that the waste generation rate in $\mathrm{kg}$ /day for outpatient estimation has high variation compared to the estimation in the inpatients.

The quantity of total HCW generated per day in Menellik II hospital was increased as the number of patients $(\mathrm{r}=0.835)$ and the number of beds $(\mathrm{r}=0.331)$ increased with being the former statistically significant $(\mathrm{p}<0.05)$. This result was in agreement with a study conducted by Debere et al in similar settings showed a statistically significant positive linear relationship between quantities of $\mathrm{HCW}$ generation rates and number of patients $\left(\mathrm{r}_{\mathrm{S}}=1, \mathrm{p}<0.05\right)$ as well as number of hospital beds $\left(\mathrm{r}_{\mathrm{s}}=0.943, \mathrm{p}<0.05\right)[13]$. It was also supported by another study conducted by Haile Michael et al, the quantity of waste generated per day increased as the number of patients and bed occupancy increased with the latter statistically significant $(p<0.001)[18]$. In a study by Komilis et al, there was a positive correlation between the total medical waste generation rates and the number of beds [21].

On the other hand, the study showed a strong positive relation of patient flow and total $\mathrm{HCW}$ generation in outpatient case teams $\left(\mathrm{R}^{2}=0.859, \mathrm{P}<0.01\right)$, than inpatients $\left(\mathrm{R}^{2}=0.109\right.$, $\mathrm{p}=0.468$, not significant) in spite of the magnitude of waste generated. This was contrast to the result found by Tesfahune et al that explained stronger positive correlation of healthcare waste generation rate with the number of inpatients $(\mathrm{r}=0.842, P<0.0001)$ than with the number of outpatients $(\mathrm{r}=0.538, P<0.0001)$ [14]. This is owing to the number of sample size in Tesfahune et al was larger used nine hospitals in large geographical area could result strong statistical association and other factors like season of year and average length of stay might be other potential reason for the difference. Average length of stay was larger in inpatients could result stable number of patients during study period might cause weak association in inpatients. There for, average length of stay which increased amount of HCW generated for the period could not be a guarantee for strong correlations between patient load and generation rate.

This study was not without limitations. Not considering seasonal variation of generations. In non-harvesting and episodic seasons of the year the patient load might increase which in turn affects the generation.

\section{Conclusion}

The mean healthcare waste generation rate of the hospital was comparable in amount to other studies in Ethiopia but higher than Sub Saharan African countries with similar setting. The number of patients treated in the hospital was the main significant factor affecting the hospital healthcare waste generation rates. It was found that when the number of patients increased, the generation rate also increased $(\mathrm{r}=0.835, \mathrm{P}<0.05)$. Infectious waste, general, sharps, pharmaceutical, pathological and radiological wastes were the types of healthcare waste generated in the hospital. However, the generation of hazardous waste was nearly 1.5 times that of general waste $(\mathrm{t}=2.796, \mathrm{P}<0.05)$, four times the WHO threshold estimation, indicated segregation was poorly practiced as a result the health care waste leaving from the hospital as a whole was both potentially infectious and hazardous. The generation rate also varies among different specialized case teams. Regular collection and consistent determination of data on healthcare waste in the hospital could be the base for establishing safe waste management system that must be adopted in the hospital.

\section{References}

[1] Healthcare without harm. Best Practices in Healthcare Waste Management Examples from Four Philippine Hospitals. Metro Manila, Philippines: February 2007.

[2] Ahmed NO, Gasmelseed GA, Musa AE. Assessment of Medical Solid Waste Management in Khartoum State Hospitals Journal of Applied and Industrial Sciences. 2014; 2 (4): 201-5.

[3] Azage, M. \& Kumie, A. Healthcare waste generation and its management system: the case of health centers in West Gojjam Zone, Amhara Region, Ethiopia. Ethiop J Health Dev.2010; 24: 120-6.

[4] Kumar R, Gorar ZA, Ahmed J, Ali Z, Chandio AK, Magan M, et al. Assessment of health care waste management practices and knowledge among healthcare workers working at tertiary care setting of Pakistan. J Health Res. August 2013; 27 (4): 233-6. 
[5] Akter N. Medical Waste Management: A ReviewJanuary, 2000 .

[6] UN, editor The adverse effects of the movement and dumping of toxic and dangerous products and wastes on the enjoyment of human rights, Calin Georgescu. Human Rights Council, 18 th session, Agenda item 3: Promotion and protection of all human rights, civil, political, economic, social and cultural rights, including the right to development; 4 July 2011; Calin, Georgescu.

[7] Emmanuel J, editor Best Environmental practices and alternative technologies for medical waste management. Eighth International Waste Management Congress and Exhibition; June 2007 25TH to 28TH; Institute of Waste Management of Southern Africa-Kasane, Botswana.

[8] WHO. Safe health-care waste management. Geneva, SwitzerlandAugust 2004.

[9] Healthcare without harm. A Comprehensive Environmental Health Agenda for Hospitals and Health Systems Around the World. [Internate]. Google; October 12, 2011 [cited August, 2014]. Available from: https://noharm.org/sites/default/files/lib/downloads/building/G GHHA.pdf

[10] Kenya Ministry of health. The National Health Care Waste Management Plan 2008-2012.

[11] Tadesse T. Solid and Hazardous Waste ManagementAugust 2004.

[12] Desta H, Worku H, Fetene A. Assessment of the Contemporary Municipal Solid Waste Management in Urban Environment: The Case of Addis Ababa, Ethiopia. Journal of Environmental Science and Technology, 2014; 7 (2): 107-22.

[13] Debere MK, Gelaye KA, Alamdo AG, Trifa ZM. Assessment of the health care waste generation rates and its management system in hospitals of Addis Ababa, Ethiopia, 2011. BMC Public Health. 2013; 13 (28).

[14] Tesfahun E, Kumie A, Legesse W, Kloos H, Beyene A. Assessment of composition and generation rate of healthcare wastes in selected public and private hospitals of Ethiopia. WM\&R. 13 February 2014; 32 (3): 215-20.

[15] Central Statistical Agency. Summary and statistical report of the 2007 population and housing cencespopulation size by age and sex. Addis Ababa, Ethiopia2008.
[16] Tobin E, Ediagbonya T, Asogun D, Oteri A. Assessment of Healthcare Waste Management practices in Primary Health Care Facilities in a Lassa Fever Endemic Local Government Area of Edo state, Nigeria. AFRIMEDIC JournalDecember, 2013; 4, (2).

[17] WHO. Safe management of wastes from health-care activities. Prüss A, Giroult E, Rushbrook P, editors. Geneva, Switzerland1999.

[18] Haylamicheal ID, Dalvie MA, Yirsaw BD, Zegeye HA. Assessing the management of healthcare waste in Hawassa city, Ethiopia. WM\&R. 2011; 29 (8): 854-62.

[19] Ndidi N, Nelson O, Patricia O, Sunday. J. Waste management in healthcare establishments withinJos Metropolis, Nigeria. African Journal of Environmental Science and Technology December, 2009; 3 (12): 459-65.

[20] UNEP. Compendium of Technologies for Treatment/Destruction of Healthcare WasteCompiled. Osaka, Japan2012.

[21] Komilis DP, A F, Arampatzi. D, D. Papadopoulos. Hazardous medical waste generation rates of different categories of health-care facilities in Greece Crete, $3^{\text {rd }}$ International conference on international \& hazardeous waste management 2012.

[22] WHO. Safe management of wastes from health-care activities Second edition. nd, editor. Geneva, Switzerland2014.

[23] Yenesew MA, Moges HG, Woldeyohannes SM. A cross sectional study on factors associated with risk perception of healthcare workers toward healthcare waste management in health care facilities of Gondar Town, Northwest Ethiopia. Int J Infect Control 2012; 8 (3): 1-9.

[24] Srishti RA, editor Medical Waste Issues, Practices and Policy An Indian and International Perspective. Seminar on Health and the Environment Centre for Science and Environment 1998 July 6-9th; New Delhi, India.

[25] WHO. Managing Health Care Waste Disposal: Guidelines on How to Construct, Use, and Maintain a Waste Disposal Unit. Harare, Zimbabwe February 2005.

[26] Manyele SV, Lyasenga TJ. Factors affecting medical waste management in low level health facilities in Tanzania Afr $\mathrm{J}$ Environ Sci Technol May 2010; 4 (5): 304-18. 